\title{
Associations Between Teaching Effectiveness Scores and Characteristics of Presentations in Hospital Medicine Continuing Education
}

\author{
John T. Ratelle, MD, Christopher M. Wittich, MD, PharmD², Roger C. Yu, MD¹, James S. Newman, MD",
} Sarah M. Jenkins, $\mathrm{MS}^{3}$, Thomas J. Beckman, MD²

\begin{abstract}
'Division of Hospital Internal Medicine, Department of Medicine, Mayo Clinic, Rochester, Minnesota; '2Division of General Internal Medicine, Department of Medicine, Mayo Clinic, Rochester, Minnesota; ${ }^{3}$ Division of Biomedical Statistics and Informatics, Department of Health Sciences Research, Mayo Clinic, Rochester, Minnesota.
\end{abstract}

BACKGROUND: There is little research regarding characteristics of effective continuing medical education (CME) presentations in hospital medicine (HM). Therefore, we sought to identify associations between validated CME teaching effectiveness scores and characteristics of $\mathrm{CME}$ presentations in the field of HM.

DESIGN/SETTING: This was a cross-sectional study of participants and didactic presentations from a national HM CME course in 2014.

MEASUREMENTS: Participants provided CME teaching effectiveness (CMETE) ratings using an instrument with known validity evidence. Overall CMETE scores (5-point scale: 1 = strongly disagree; 5 = strongly agree) were averaged for each presentation, and associations between scores and presentation characteristics were determined using the Kruskal-Wallis test. The threshold for statistical significance was set at $P<0.05$.

RESULTS: A total of 277 out of 368 participants (75.3\%) completed evaluations for the 32 presentations. CMETE scores (mean [standard deviation]) were significantly associated with the use of audience response (4.64 [0.16]) versus no audience response (4.49 [0.16]; $P=0.01)$, longer presentations $(\geq 30$ minutes: $4.67[0.13]$ vs $<30$ minutes: 4.51 [0.18]; $P=0.02)$, and larger number of slides ( $\geq 50: 4.66$ [0.17] vs $<50: 4.55$ [0.17]; $P=0.04$ ). There were no significant associations between CMETE scores and use of clinical cases, defined goals, or summary slides.

CONCLUSIONS: To our knowledge, this is the first study regarding associations between validated teaching effectiveness scores and characteristics of effective CME presentations in HM. Our findings, which support previous research in other fields, indicate that $\mathrm{CME}$ presentations may be improved by increasing interactivity through the use of audience response systems and allowing longer presentations. Journal of Hospital Medicine 2015;10:569-573. (c) 2015 Society of Hospital Medicine
Hospital medicine (HM), which is the fastest growing medical specialty in the United States, includes more than 40,000 healthcare providers. ${ }^{1}$ Hospitalists include practitioners from a variety of medical specialties, including internal medicine and pediatrics, and professional backgrounds such as physicians, nurse practitioners. and physician assistants. ${ }^{2,3}$ Originally defined as "specialists of inpatient medicine," hospitalists must diagnose and manage a wide variety of clinical conditions, coordinate transitions of care, provide perioperative management to surgical patients, and contribute to quality improvement and hospital administration., ${ }^{4,5}$

With the evolution of the HM, the need for effective continuing medical education (CME) has become

*Address for correspondence and reprint requests: John T. Ratelle, MD, Mayo Clinic Rochester, 200 First Street SW, Rochester, MN 55905; Telephone: 507-284-3589; Fax: 507-255-9189;

E-mail: ratelle.john@mayo.edu

Additional Supporting Information may be found in the online version of this article.

Received: February 24, 2015; Revised: April 10, 2015; Accepted: April 28, 2015

2015 Society of Hospital Medicine DOI 10.1002/jhm.2391

Published online in Wiley Online Library (Wileyonlinelibrary.com). increasingly important. Courses make up the largest percentage of CME activity types, ${ }^{6}$ which also include regularly scheduled lecture series, internet materials, and journal-related CME. Successful CME courses require educational content that matches the learning needs of its participants. ${ }^{7}$ In 2006, the Society for Hospital Medicine (SHM) developed core competencies in HM to guide educators in identifying professional practice gaps for useful CME. ${ }^{8}$ However, knowing a population's characteristics and learning needs is a key first step to recognizing a practice gap. ${ }^{9}$ Understanding these components is important to ensuring that competencies in the field of HM remain relevant to address existing practice gaps. ${ }^{10}$ Currently, little is known about the demographic characteristics of participants in HM CME.

Research on the characteristics of effective clinical teachers in medicine has revealed the importance of establishing a positive learning climate, asking questions, diagnosing learners' needs, giving feedback, utilizing established teaching frameworks, and developing a personalized philosophy of teaching. ${ }^{11}$ Within CME, research has generally demonstrated that courses lead to improvements in lower level outcomes, ${ }^{12}$ such as 


\section{TABLE 1. Participant Characteristics}

\begin{tabular}{|c|c|}
\hline Variable & No. of Attendees (\%), N = 277 \\
\hline \multicolumn{2}{|l|}{ Sex } \\
\hline Unknown & 22 \\
\hline Male & $124(48.6 \%)$ \\
\hline Female & $131(51.4 \%)$ \\
\hline \multicolumn{2}{|l|}{ Age } \\
\hline Unknown & 17 \\
\hline $20-29$ years & $11(4.2 \%)$ \\
\hline $30-39$ years & $83(31.9 \%)$ \\
\hline 40-49 years & $61(23.5 \%)$ \\
\hline $50-59$ years & $56(21.5 \%)$ \\
\hline $60-69$ years & $38(14.6 \%)$ \\
\hline $70+$ years & $11(4.2 \%)$ \\
\hline \multicolumn{2}{|l|}{ Professional degree } \\
\hline Unknown & 20 \\
\hline MD/MBBS & $181(70.4 \%)$ \\
\hline DO & $23(8.9 \%)$ \\
\hline NP & $28(10.9 \%)$ \\
\hline PA & $24(9.3 \%)$ \\
\hline Other & $1(0.4 \%)$ \\
\hline \multicolumn{2}{|l|}{ Medical specialty } \\
\hline Unknown & 26 \\
\hline Internal medicine & $149(59.4 \%)$ \\
\hline Family medicine & $47(18.7 \%)$ \\
\hline IM subspecialty & $14(5.6 \%)$ \\
\hline Other & $41(16.3 \%)$ \\
\hline \multicolumn{2}{|l|}{ Geographic location } \\
\hline Unknown & 16 \\
\hline Western US & $48(18.4 \%)$ \\
\hline Northeastern US & $33(12.6 \%)$ \\
\hline Midwestern US & $98(37.5 \%)$ \\
\hline Southern US & $40(15.3 \%)$ \\
\hline Canada & $13(5.0 \%)$ \\
\hline Other & $29(11.1 \%)$ \\
\hline \multicolumn{2}{|l|}{ Years of practice/training } \\
\hline Unknown & 16 \\
\hline Currently in training & $1(0.4 \%)$ \\
\hline Practice 0-4 years & $68(26.1 \%)$ \\
\hline Practice 5-9 years & $55(21.1 \%)$ \\
\hline Practice $10-19$ years & $64(24.5 \%)$ \\
\hline Practice $20+$ years & $73(28.0 \%)$ \\
\hline \multicolumn{2}{|l|}{ Practice setting } \\
\hline Unknown & 23 \\
\hline Academic & $63(24.8 \%)$ \\
\hline Private-urban & $99(39.0 \%)$ \\
\hline Private-rural & $49(19.3 \%)$ \\
\hline Other & $43(16.9 \%)$ \\
\hline \multicolumn{2}{|l|}{ ABIM certification HM } \\
\hline Unknown & 22 \\
\hline Yes & $48(18.8 \%)$ \\
\hline № & $207(81.2 \%)$ \\
\hline \multicolumn{2}{|l|}{ Hospitalist } \\
\hline Unknown & 20 \\
\hline Yes & $181(70.4 \%)$ \\
\hline № & $76(29.6 \%)$ \\
\hline \multicolumn{2}{|l|}{ CME credits claimed } \\
\hline Unknown & 20 \\
\hline $0-24$ & $54(21.0 \%)$ \\
\hline $25-49$ & $105(40.9 \%)$ \\
\hline $50-74$ & $61(23.7 \%)$ \\
\hline $75-99$ & $15(5.8 \%)$ \\
\hline $100+$ & $22(8.6 \%)$ \\
\hline \multicolumn{2}{|l|}{ CME programs attended } \\
\hline Unknown & 18 \\
\hline 0 & $38(14.7 \%)$ \\
\hline $1-2$ & $166(64.1 \%)$ \\
\hline
\end{tabular}

TABLE 1. Continued

\begin{tabular}{cc}
\hline Variable & No. of Attendees (\%), N=277 \\
\hline $3-5$ & $52(20.1 \%)$ \\
$6+$ & $3(1.2 \%)$
\end{tabular}

NOTE: Abbreviations: ABIM, American Board of Internal Medicine; CME, continuing medical education; DO, doctor of osteopathic medicine; HM, hospital medicine; IM, internal medicine; MBBS, bachelor of medicine, bachelor of surgery; MD, medical doctor; NP, nurse practitioner; PA, physician assistant.

satisfaction and learning, yet higher level outcomes such as behavior change and impacts on patients are inconsistent. ${ }^{13-15}$ Additionally, we have shown that participant reflection on CME is enhanced by presenters who have prior teaching experience and higher teaching effectiveness scores, by the use of audience participation and by incorporating relevant content. ${ }^{16,17}$ Despite the existence of research on CME in general, we are not aware of prior studies regarding characteristics of effective CME in the field of HM.

To better understand and improve the quality of HM CME, we sought to describe the characteristics of participants at a large, national HM CME course, and to identify associations between characteristics of presentations and CME teaching effectiveness (CMETE) scores using a previously validated instrument.

\section{METHODS}

\section{Study Design and Participants}

This cross-sectional study included all participants $(\mathrm{n}=368)$ and presenters $(\mathrm{n}=29)$ at the Mayo Clinic Hospital Medicine Managing Complex Patients (MCP) course in October 2014. MCP is a CME course designed for hospitalists (defined as those who spend most of their professional practice caring for hospitalized patients) and provides up to 24.5 American Medical Association Physician's Recognition Award category 1 credits. The course took place over 4 days and consisted of 32 didactic presentations, which comprised the context for data collection for this study. The structure of the course day consisted of early and late morning sessions, each made up of 3 to 5 presentations, followed by a question and answer session with presenters and a 15 -minute break. The study was deemed exempt by the Mayo Clinic Institutional Review Board.

\section{Independent Variables: Characteristics of Participants and Presentations}

Demographic characteristics of participants were obtained through anonymous surveys attached to CME teaching effectiveness forms. Variables included participant sex, professional degree, self-identified hospitalist, medical specialty, geographic practice location, age, years in practice/level of training, practice setting, American Board of Internal Medicine (ABIM) certification of Focused Practice in Hospital Medicine, 
number of CME credits earned, and number of CME programs attended in the past year. These variables were selected in an effort to describe potentially relevant demographics of a national cohort of HM CME participants.

Presentation variables included use of clinical cases, audience response system (ARS), number of slides, defined goals/objectives, summary slide and presentation length in minutes, and are supported by previous CME effectiveness research. ${ }^{16-19}$

\begin{tabular}{|c|c|c|c|c|}
\hline Presentation Variable & No. (\%) & $\begin{array}{l}\text { Mean } \\
\text { Score }\end{array}$ & $\begin{array}{l}\text { Standard } \\
\text { Deviation }\end{array}$ & $\begin{array}{c}P \\
\text { Value }\end{array}$ \\
\hline \multicolumn{5}{|l|}{ Use of clinical cases } \\
\hline Yes & $28(87.5 \%)$ & 4.60 & 0.18 & \multirow[t]{2}{*}{0.14} \\
\hline No & $4(12.5 \%)$ & 4.49 & 0.14 & \\
\hline \multicolumn{5}{|l|}{ Audience response system } \\
\hline Yes & $20(62.5 \%)$ & 4.64 & 0.16 & \multirow[t]{2}{*}{0.01} \\
\hline No & $12(37.5 \%)$ & 4.49 & 0.16 & \\
\hline \multicolumn{5}{|l|}{ NNo. of slides } \\
\hline$\geq 50$ & $10(31.3 \%)$ & 4.66 & 0.17 & \multirow[t]{2}{*}{0.04} \\
\hline$<50$ & $22(68.8 \%)$ & 4.55 & 0.17 & \\
\hline \multicolumn{5}{|l|}{ Defined goals/objectives } \\
\hline Yes & $29(90.6 \%)$ & 4.58 & 0.18 & \multirow[t]{2}{*}{0.87} \\
\hline NNo & $3(9.4 \%)$ & 4.61 & 0.17 & \\
\hline \multicolumn{5}{|l|}{ Summary slide } \\
\hline Yes & $22(68.8 \%)$ & 4.56 & 0.18 & \multirow[t]{2}{*}{0.44} \\
\hline № & $10(31.3 \%)$ & 4.62 & 0.15 & \\
\hline \multicolumn{5}{|l|}{ Presentation length } \\
\hline$\geq 30$ minutes & $14(43.8 \%)$ & 4.67 & 0.13 & \multirow[t]{2}{*}{0.02} \\
\hline$<30$ minutes & $18(56.3 \%)$ & 4.51 & 0.18 & \\
\hline
\end{tabular}

\section{Outcome Variable: CME Teaching Effectiveness Scores}

The CMETE scores for this study were obtained from an instrument described in our previous research. ${ }^{16}$ The instrument contains 7 items on 5-point scales (range: strongly disagree to strongly agree) that address speaker clarity and organization, relevant content, use of case examples, effective slides, interactive learning methods (eg, audience response), use of supporting evidence, appropriate amount of content, and summary of key points. Additionally, the instrument includes 2 open-ended questions: (1) What did the speaker do well? (Please describe specific behaviors and examples) and (2) What could the speaker improve on? (Please describe specific behaviors and examples). Validity evidence for CMETE scores included factor analysis demonstrating a unidimensional model for measuring presenter feedback, along with excellent internal consistency and inter-rater reliability. ${ }^{16}$

\section{Data Analysis}

A CMETE score per presentation from each attendee was calculated as the average over the 7 instrument items. A composite presentation-level CMETE score was then computed as the average overall score within each presentation. CMETE scores were summarized using means and standard deviations (SDs). The overall CMETE scores were compared by presentation characteristics using Kruskal-Wallis tests. To illustrate the size of observed differences, Cohen effect sizes are presented as the average difference between groups divided by the common SD. All analyses were performed using SAS version 9 (SAS Institute Inc., Cary, NC).

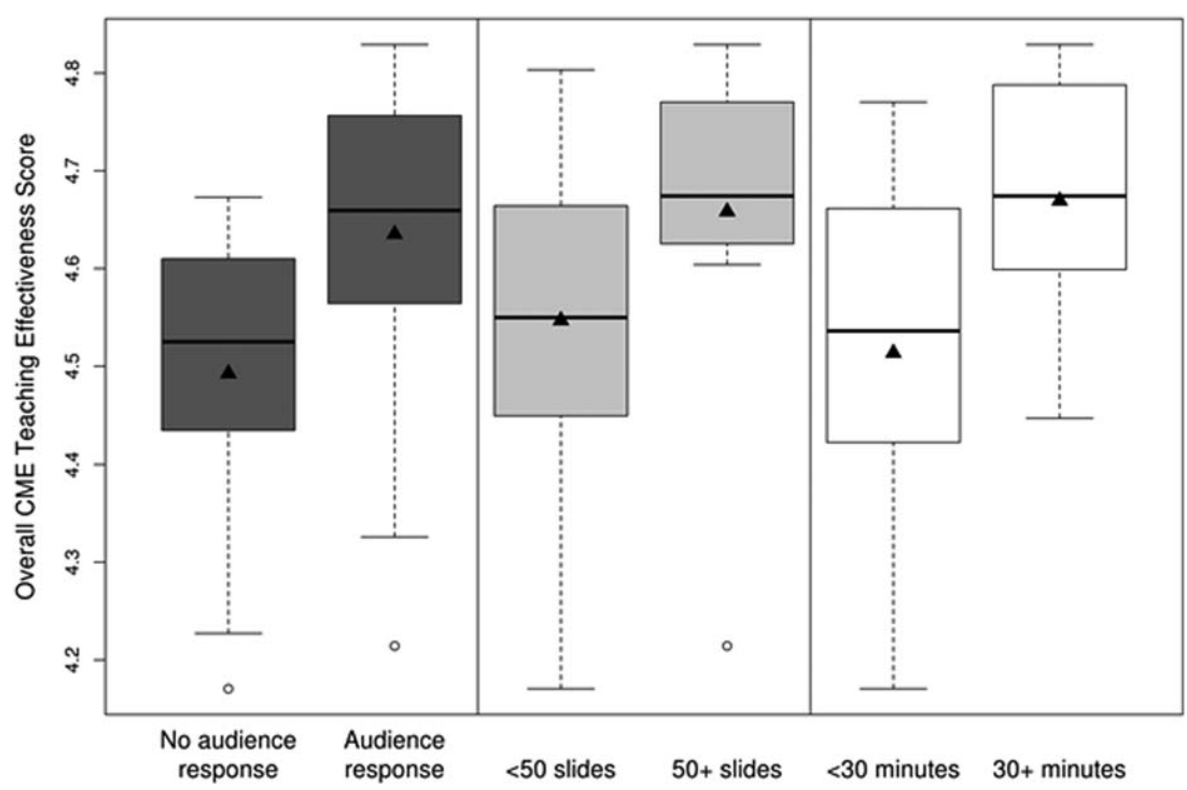

FIG. 1. Overall teaching effectiveness score distribution by audience response, number of slides, and presentation length. The boxes represent the interquartile range (IQR) (25th to 75th percentiles) with the median (middle horizontal line) and mean (triangle). The dashed lines extend to the last observation within a distance equal to $1.5^{\star} \mathrm{IQR}$ from the top and bottom of the box. Any observations beyond that distance are plotted separately. Abbreviations: CME, continuing medical education. 


\section{RESULTS}

There were 32 presentations during the MCP conference in 2014. A total of 277 (75.2\%) out of 368 participants completed the survey. This yielded 7947 CMETE evaluations for analysis, with an average of 28.7 per person (median: 31, interquartile range: $27-$ 32, range: 6-32).

Demographic characteristics of course participants are listed in Table 1. Participants (number, \%), described themselves as hospitalists (181, 70.4\%), ABIM certified with HM focus $(48,18.8 \%)$, physicians with MD or MBBS degrees $(181,70.4 \%)$, nurse practitioners or physician assistants $(52 ; 20.2 \%)$, and in practice $\geq 20$ years $(73,28 \%)$. The majority of participants $(148,58.3 \%)$ worked in private practice, whereas only $63(24.8 \%)$ worked in academic settings.

CMETE scores (mean [SD]) were significantly associated with the use of ARS (4.64 [0.16]) vs no ARS (4.49 [0.16]; $P=0.01$, Table 2, Figure 1), longer presentations ( $\geq 30$ minutes: 4.67 [0.13] vs $<30$ minutes: 4.51 [0.18]; $P=0.02)$, and larger number of slides $(\geq 50: 4.66[0.17]$ vs $<50: 4.55$ [0.17]; $P=0.04)$. There were no significant associations between CMETE scores and use of clinical cases, defined goals, or summary slides.

The magnitude of score differences observed in this study are substantial when considered in terms of Cohen's effect sizes. For number of slides, the effect size is 0.65 , for audience response the effect size is 0.94, and for presentation length the effect size is approximately 1 . According to Cohen, effect sizes of 0.5 to 0.8 are moderate, and effect sizes $>0.8$ are large. Consequently, the effect sizes of our observed differences are moderate to large. ${ }^{20,21}$

\section{DISCUSSION}

To our knowledge, this is the first study to measure associations between validated teaching effectiveness scores and characteristics of presentations in HM CME. We found that the use of ARS and longer presentations were associated with significantly higher CMETE scores. Our findings have implications for HM CME course directors and presenters as they attempt to develop methods to improve the quality of CME.

CME participants in our study crossed a wide range of ages and experience, which is consistent with national surveys of hospitalists. ${ }^{22,23}$ Interestingly, however, nearly 1 in 3 participants trained in a specialty other than internal medicine. Additionally, the professional degrees of participants were diverse, with $20 \%$ of participants having trained as nurse practitioners or physician assistants. These findings are at odds with an early national survey of inpatient practitioners, ${ }^{22}$ but consistent with recent literature that the diversity of training backgrounds among hospitalists is increasing as the field of HM evolves. ${ }^{24}$ Hospital medicine CME providers will need to be cognizant of these demographic changes as they work to identify practice gaps and apply appropriate educational methods.
The use of an ARS allows for increased participation and engagement among lecture attendees, which in turn promotes active learning. ${ }^{25-27}$ The association of higher teaching scores with the use of ARS is consistent with previous research in other CME settings such as clinical round tables and medical grand rounds. ${ }^{17,28}$ As it pertains to HM specifically, our findings also build upon a recent study by Sehgal et al., which reported on the novel use of bedside CME to enhance interactive learning and discussion among hospitalists, and which was viewed favorably by course participants. ${ }^{29}$

The reasons why longer presentations in our study were linked to higher CMETE scores are not entirely clear, as previous CME research has failed to demonstrate this relationship. ${ }^{18}$ One possibility is that course participants prefer learning from presentations that provide granular, content-rich information. Another possibility may be that characteristics of effective presenters who gave longer presentations and that were not measured in this study, such as presenter experience and expertise, were responsible for the observed increase in CMETE scores. Yet another possibility is that effective presentations were longer due to the use of ARS, which was also associated with better CMETE scores. This explanation may be plausible because the ARS requires additional slides and provides opportunities for audience interaction, which may lengthen the duration of any given presentation.

This study has several limitations. This was a single CME conference sponsored by a large academic medical center, which may limit generalizability, especially to smaller conferences in community settings. However, the audience was large and diverse in terms of participants' experiences, practice settings, professional backgrounds, and geographic locations. Furthermore, the demographic characteristics of hospitalists at our course appear very similar to a recently reported national cross-section of hospitalist groups. ${ }^{30}$ Second, this is a cross-sectional study without a comparison group. Nonetheless, a systematic review showed that most published education research studies involved single-group designs without comparison groups. ${ }^{31}$ Last, the outcomes of the study include attitudes and objectively measured presenter behaviors such as the use of ARS, but not patientrelated outcomes. Nonetheless, evidence indicates that the majority of medical education research does not present outcomes beyond knowledge, ${ }^{31}$ and it has been noted that behavior-related outcomes strike the ideal balance between feasibility and rigor. ${ }^{32,33}$ Finally, the instrument used in this study to measure teaching effectiveness is supported by prior validity evidence. $^{16}$

In summary, we found that hospital medicine CME presentations, which are longer and use audience responses, are associated with greater teaching 
effectiveness ratings by CME course participants. These findings build upon previous CME research and suggest that CME course directors and presenters should strive to incorporate opportunities that promote audience engagement and participation. Additionally, this study adds to the existing validity of evidence for the CMETE assessment tool. We believe that future research should explore potential associations between teacher effectiveness and patient-related outcomes, and determine whether course content that reflects the SHM core competencies improves CME teaching effectiveness scores.

Disclosure: Nothing to report.

\section{References}

1. Society of Hospital Medicine. 2013/2014 press kit. Available at: http:// www.hospitalmedicine.org/Web/Media_Center/Web/Media_Center/ Media_Center.aspx?hkey=e26ceba7-ba93-4e50-8eb1-1ccc75d6f0fd. Accessed May 18, 2015

2. Kleinpell RM, Hanson NA, Buchner BR, Winters R, Wilson MJ, Keck AC. Hospitalist services: an evolving opportunity. Nurse Pract. 2008; 33:9-10.

3. Wall S, Scudamore D, Chin J, et al. The evolving role of the pediatric nurse practitioner in hospital medicine. J Hosp Med. 2014;9:261-265.

4. Wachter RM, Goldman L. The emerging role of "hospitalists" in the American health care system. N Engl J Med. 1996;335:514-517.

5. Society of Hospital Medicine. Definition of a hospitalist and hospital medicine. Available at: http://www.hospitalmedicine.org/Web/About SHM/Hospitalist_Definition/Web/About_SHM/Industry/Hospital_ Medicine_Hospital_Definition.aspx. Accessed February 16, 2015.

6. Accreditation Council for Continuing Medical Education. 2013 annual report data executive summary. Available at: http://www. accme.org/sites/default/files/630_2013_Annual_Report_20140715_0. pdf. Accessed February 16, $201 \overline{5}$.

7. Muroff LR. The anatomy of an outstanding CME meeting. J Am Coll Radiol. 2005;2:534-540.

8. McKean SC, Budnitz TL, Dressler DD, Amin AN, Pistoria MJ. How to use The Core Competencies in Hospital Medicine: a framework for curriculum development. J Hosp Med. 2006;1:57-67.

9. Wittich CM, Chutka DS, Mauck KF, Berger RA, Litin SC, Beckman TJ. Perspective: a practical approach to defining professional practice gaps for continuing medical education. Acad Med. 2012;87:582-585.

10. Dressler DD, Pistoria MJ, Budnitz TL, McKean SC, Amin AN. Core competencies in hospital medicine: development and methodology. J Hosp Med. 2006;1(suppl 1):148-156.

11. Beckman TJ, Lee MC. Proposal for a collaborative approach to clinical teaching. Mayo Clin Proc. 2009;84:339-344.

12. Beckman TJ, Cook DA. Developing scholarly projects in education: a primer for medical teachers. Med Teach. 2007;29:210-218.

13. Mansouri M, Lockyer J. A meta-analysis of continuing medical education effectiveness. J Contin Educ Health Prof. 2007;27:6-15.
14. Moore DE Jr, Green JS, Gallis HA. Achieving desired results and improved outcomes: integrating planning and assessment throughout learning activities. J Contin Educ Health Prof. 2009;29:1-15.

15. Cervero RM, Gaines JK. Effectiveness of continuing medical education: updated synthesis of systematic reviews. Available at: http:// www.accme.org/sites/default/files/652_20141104_Effectiveness_of Continuing_Medical_Education_Cervero_and_Gaines.pdf. Accessed March 25, 2015.

16. Wittich CM, Mauck KF, Mandrekar JN, et al. Improving participant feedback to continuing medical education presenters in internal medicine: a mixed-methods study. J Gen Intern Med. 2012;27:425-431.

17. Wittich CM, Szostek JH, Reed DA, et al. Measuring faculty reflection on medical grand rounds at Mayo Clinic: associations with teaching experience, clinical exposure, and presenter effectiveness. Mayo Clin Proc. 2013;88:277-284.

18. Copeland HL, Longworth DL, Hewson MG, Stoller JK. Successful lecturing: a prospective study to validate attributes of the effective medical lecture. J Gen Intern Med. 2000;15:366-371.

19. Shewchuk RM, Schmidt HJ, Benarous A, Bennett NL, Abdolrasulnia M, Casebeer LL. A standardized approach to assessing physician expectations and perceptions of continuing medical education. J Contin Educ Health Prof. 2007;27:173-182.

20. Cohen J. Statistical Power Analysis for the Behavioral Sciences. New York, NY: Academic Press; 1977.

21. Cohen J. Statistical Power Analysis for the Behavioral Sciences. 2nd ed. Hillsdale, NJ: Erlbaum; 1988.

22. Lindenauer PK, Pantilat SZ, Katz PP, Wachter RM. Hospitalists and the practice of inpatient medicine: results of a survey of the National Association of Inpatient Physicians. Ann Intern Med. 1999;130:343-349.

23. Hinami K, Whelan CT, Wolosin RJ, Miller JA, Wetterneck TB. Worklife and satisfaction of hospitalists: toward flourishing careers. J Gen Intern Med. 2012;27:28-36.

24. Kartha A, Restuccia JD, Burgess JF Jr, et al. Nurse practitioner and physician assistant scope of practice in 118 acute care hospitals. J Hosp Med. 2014;9:615-620.

25. Cain J, Robinson E. A primer on audience response systems: current applications and future considerations. Am J Pharm Educ. 2008;72:77.

26. Davis N, Davis D, Bloch R. Continuing medical education: AMEE education guide no 35. Med Teach. 2008;30:652-666.

27. Caldwell JE. Clickers in the large classroom: current research and best-practice tips. CBE Life Sci Educ. 2007;6:9-20.

28. Miller RG, Ashar BH, Getz KJ. Evaluation of an audience response system for the continuing education of health professionals. J Contin Educ Health Prof. 2003;23:109-115.

29. Sehgal NL, Wachter RM, Vidyarthi AR. Bringing continuing medical education to the bedside: the University of California, San Francisco Hospitalist Mini-College. J Hosp Med. 2014;9:129-134.

30. Society of Hospital Medicine. 2014 State of Hospital Medicine Report. Philadelphia, PA: Society of Hospital Medicine; 2014.

31. Reed DA, Cook DA, Beckman TJ, Levine RB, Kern DE, Wright SM. Association between funding and quality of published medical education research. JAMA. 2007;298:1002-1009.

32. Shea JA. Mind the gap: some reasons why medical education research is different from health services research. Med Educ. 2001;35:319320.

33. Cook DA, Beckman TJ. Reflections on experimental research in medical education. Adv Health Sci Educ Theory Pract. 2010;15: $455-464$. 